\title{
LA IGLESIA DE SAN BERNARDO DE SEVILLA Y SU ENTORNO: LOS TEMPLOS ANTERIORES
}

\section{THE SEVILLIAN CHURCH OF SAN BERNARDO AND ITS ENVIRONMENT: THE PREVIOUS TEMPLES}

\author{
Teodoro Falcón Márquez \\ Universidad de Sevilla. España \\ ORCID: 0000-0002-1300-708X \\ tfm@us.es
}

\begin{abstract}
El templo actual de San Bernardo marca la transición entre la arquitectura barroca a la neoclásica en la ciudad de Sevilla. Se edificó entre 1780 y 1785, según proyecto del arquitecto diocesano José Álvarez. En este artículo se dan noticias de los dos templos anteriores y de su barrio. En primer lugar, se erigió una ermita en el siglo XIII, que debió estar fortificada por hallarse a extramuros. A comienzos del siglo XVII, se edificó una iglesia de estilo manierista, en la que intervinieron los arquitectos Asensio de Maeda y Miguel de Zumárraga. Se derribó en 1780 para edificarse el templo actual, de mayores proporciones, incorporando el solar de unas casas. Álvarez.

Palabras clave: arquitectura barroca; Sevilla; Asensio de Maeda; Miguel de Zumárraga; José

The current San Bernardo Temple marks the transition between Baroque and Neoclassical architecture in the city of Seville. It was built between 1780 and 1785, according to the project of the diocesan architect José Álvarez. This paper gives news of the two previous temples and their neighborhood. First, a hermitage was erected in the $13^{\text {th }}$ century, which should have been fortified, because it was located outside the city walls. At the beginning of the $17^{\text {th }}$ century, a Mannerist style church was built, in which the architects Asensio de Maeda and Miguel de Zumárraga took part. It was demolished in 1780 to build the current temple, of greater proportions, incorporating the lot of some houses.

Keywords: Baroque architecture; Seville; Asensio de Maeda; Miguel de Zumárraga; José Álvarez.
\end{abstract}

\section{INTRODUCCIÓN}

La iglesia de San Bernardo se encuentra en el barrio del que ha recibido su nombre, al sureste de la ciudad. Cuando surgió estaba situada a extramuros. El 
núcleo central del barrio primitivo, en torno al templo, se ha ido perfilando en la Edad Moderna con forma de un cuadrilátero irregular, configurado entre dos arterias orientadas teóricamente de norte a sur: calle San Bernardo, al oeste, y Marqués de Estella, al este, además de las calles Almonacid y Santísimo Cristo de la Salud, en el interior. Las calles transversales oeste-este son Cofia, Gallinato, Alonso Tello y Santo Rey y, por el sur, Campamento y Tentudía. El templo ocupa en la actualidad la mitad de una manzana, delimitada por las calles Santo Rey, Cristo de la Salud y Alonso Tello. No tiene la orientación preceptiva, ya que se organiza de sur a norte. La fachada principal, a los pies, y la casa rectoral anexa dan a la calle Santo Rey, donde se encuentra también, enfrente, la nueva sede de la hermandad de penitencia del Cristo de la Salud. En el siglo XVII esta calle se denominaba del Bizcocho o del Horno del Bizcocho. En el siglo XIX el Ayuntamiento rotuló las calles de su entorno con nombres relacionados con Fernando III el Santo en recuerdo de que en este lugar se estableció el campamento del rey conquistador durante el asedio de la ciudad. El lado del evangelio de la iglesia da a la calle Santísimo Cristo de la Salud, por la imagen titular de la hermandad de penitencia que radica en este templo. La hermandad tuvo su origen en 1748, aunque sus primeras reglas datan de 1764. El tramo meridional de esta vía, llamada Almonacid, recibe el nombre por un comendador que participó en la Reconquista. En el siglo XVII toda esta arteria se llamaba plazuela de San Bernardo o de la Iglesia y, más tarde, Nueva, después del estreno del templo. La calle Alonso Tello, que tomó ese nombre por otro personaje de época fernandina, se halla tras la cabecera del templo y de la antigua sede de la hermandad sacramental. Esta vía separa la iglesia de la Real Fundición de Artillería. El resto de la manzana, que da a la calle Marqués de Estella (antes Ocho Hornos), la ocupan diferentes viviendas que ocultan el lado de la epístola del templo.

Se trata de un edificio que marca una inflexión en la evolución de la arquitectura sevillana del siglo XVIII. Por una parte, es la última iglesia del barroco, edificada entre 1780 y 1785 , al mismo tiempo que por su interior es la primera de estilo neoclásico de la ciudad. En la historiografía artística este edificio ha recibido elogios en estos últimos siglos. González de León (1844) ha dicho que "este templo moderno es mejor que las otras parroquias de la ciudad". Para Gestoso (1892), desde su óptica académica, es este templo "uno de los más hermosos de Sevilla por sus grandes y sencillos trazos, el cual obedece a las severas prácticas de la segunda restauración del estilo greco-romano"”. Sancho Corbacho (1952) considera esta iglesia "como la última de importancia entre las construidas en la

${ }^{1}$ GONZÁlEZ DE LEÓN, Félix: Noticia artística de todos los edificios públicos de esta muy noble ciudad de Sevilla. Sevilla, 1844, p. 537.

${ }^{2}$ GESTOSO Y PÉREZ, José: Sevilla monumental y artística. T. I. Sevilla, 1892, pp. 453-454. 
capital con verdadero carácter sevillano"3. Está declarada como Bien de Interés Cultural (B.I.C.), según consta en el BOJA de 9 de noviembre de 1995.

En el lugar que ocupa la actual iglesia, de fines del siglo XVIII, hubo dos templos anteriores. El primero fue una ermita erigida tras la Reconquista. Después se comenzó a edificar una iglesia parroquial a fines del siglo XVI. De ninguna de ellas se ha escrito alguna monografía. Por nuestra parte vamos a aportar algunos datos de los edificios anteriores. A causa, por tanto, de que nos vamos a centrar en el aspecto arquitectónico, citaremos como punto de partida qué es lo que habían aportado hasta ahora algunos historiadores. Gestoso da la noticia de que a partir de 1593 se inició la anterior iglesia parroquial, y que el actual templo fue bendecido por el canónigo magistral don Marcelo Félix Doye el 18 de agosto de $1785^{4}$. Sancho Corbacho documentó que el autor del proyecto de este edificio fue José Álvarez ${ }^{5}$. Recientemente ha sido el arquitecto Higuera Meléndez quien al publicar un artículo sobre Álvarez facilita algunos datos documentales sobre esta iglesia, publicando la planta original ${ }^{6}$. Debido tal vez a su situación a extramuros, no suele figurar este templo en la abundante iconografía existente sobre la ciudad, que generalmente está tomada desde la margen derecha del Guadalquivir, es decir, desde Triana.

\section{DE ERMITA A CAPILLA DE LA CATEDRAL}

Los orígenes del barrio de San Bernardo de Sevilla se remontan a la Reconquista, a raíz del establecimiento en este lugar de un campamento por Fernando III el Santo el 20 de agosto de 1247, día de la festividad de San Bernardo Abad, en el curso del asedio de la ciudad ${ }^{7}$. A partir de entonces comenzó a surgir aquí un arrabal en torno a una ermita. El barrio, que fue generalmente de población modesta, se fue dotando paulatinamente de una serie de pequeñas construcciones industriales que favorecieron paulatinamente el aumento de sus habitantes y la construcción de nuevas viviendas. Entre las industrias hay que destacar el Matadero (1489) y los talleres de fundición de los Morel. Juan Morel los fundó en torno a 1540 como fábrica de cañones de bronce. Su hijo Bartolomé en la década de 1560 realizó el Giraldillo, campanas y jarras - con posterioridad de azucenas- de la Giralda, el tenebrario y piezas para el facistol de la catedral. El edificio sería con

${ }^{3}$ SANCHO CORBACHO, Antonio: Arquitectura barroca sevillana del siglo XVIII. Madrid, 1952, p. 255.

${ }^{4}$ GESTOSO Y PÉREZ, José: Sevilla monumental..., op. cit., pp. 453-456.

5 SANCHO CORBACHO, Antonio: Arquitectura barroca ..., op. cit., p. 255.

${ }^{6}$ HIGUERA MELÉNDEZ, José Manuel: “José Álvarez (1723-1800), maestro mayor de obras del arzobispado de Sevilla", Isidorianum, 50, 2016, pp. 353-384.

7 ESPINOSA DE LOS MONTEROS, Pablo: Historia, antigüedades y grandezas... de Sevilla. Sevilla, 1627, lib. $4^{\circ}$, ff. 132-136. 
posterioridad adquirido por el Estado en 1634, experimentado a lo largo del siglo XVIII varias ampliaciones durante los reinados de Felipe V y Carlos III. Destacaremos las llevadas a cabo por Próspero Verbom e Ignacio Sala en 1725, la de Jean Maritz en 1777 y, finalmente, la del arquitecto Vicente de San Martín entre 1782-1786 coincidiendo con la construcción del nuevo templo de San Bernardo ${ }^{8}$. Además existían en el barrio hornos cerámicos, ollerías y molinos de agua para el trigo; también había cultivo de cáñamo. La marginalidad de este pequeño núcleo de población estuvo condicionada desde sus orígenes por su ubicación a extramuros, frente a la Puerta de la Carne, y por hallarse situado en la margen izquierda del arroyo Tagarete, que, tras fluir canalizado desde el siglo XIX por la calle San Fernando, desemboca al pie de la Torre del Oro. El arroyo se cruzaba por algunos puentes, entre los que se citan el de "La alcantarilla" y "La puente horadada".

Por este sector estuvo el cementerio judío. Según los restos arqueológicos surgidos a partir de la década de 1990, esa necrópolis se extendía a lo largo de una gran área existente entre la Puerta de la Carne (de la Judería o de Min Joar), el aparcamiento subterráneo de la calle Cano y Cueto, el antiguo cuartel de Intendencia, antes de Caballería (ahora Diputación Provincial), las calles Campamento y Tentudía, en el barrio de San Bernardo, así como también por el sector de la Buhaira. Todavía en el siglo XVI eran visibles las tumbas, que fueron saqueadas a mediados de ese siglo para reutilizar sus materiales o buscar joyas. Se han conservado algunos epitafios, entre ellos el de un rabino célebre, fechado en $1341^{9}$. Morgado nos informa también de la aparición en 19 de marzo de 1566 de dos sepulcros de mármol en el arrabal de San Bernardo ${ }^{10}$. A la histórica

${ }^{8}$ SANCHO CORBACHO, Antonio: Arquitectura barroca..., op. cit., pp. 352-353; RABANAL YUS, Aurora: "El reinado de Carlos III en la arquitectura de las Reales Fundiciones Españolas", Fragmentos, 12-13-14, 1988, pp. 103-113; MORALES SÁNCHEZ, José: La Real Fábrica de Tabacos. Arquitectura, territorio y ciudad en la Sevilla del siglo XVIII. Sevilla, 1991, pp. 407-410; DE LA VEGA VIGUERA, Enrique: Sevilla y la Real Fundición de Cañones. Sevilla, 1992; MORA PIRIS, Pedro: La Real Fundición de bronce de Sevilla. Sevilla, 1994; y CRUCES BLANCO, Esther: "Imágenes y palabras: La interpretación de documentos para los estudios de arqueología, arquitectura e iconografía. El Archivo de la Real Fábrica de Artillería de Sevilla", en Arquitectura e Iconografía artística militar en España y América (siglos XV-XVIII).T. III. Sevilla, 1999, pp. 45-55.

9 CARO, Rodrigo: Antigüedades y principado de la ilustre ciudad de Sevilla y corografía de su convento jurídico o antigua Chancillería. Sevilla, 1634; FITA COLOMÉ, Fidel: "El cementerio hebreo de Sevilla. Epitafio de un rabino célebre", Boletín de la Real Academia de la Historia, XVII, 1887, pp. 174-183; GONZÁLEZ, Julio: El Repartimiento de Sevilla. Madrid, 1951 (reed. Sevilla, 1993), p. 363; y SANTANA FALCÓN, Isabel: "Excavaciones arqueológicas en el cementerio de la Aljama judía de Sevilla (1992-2006)", Anales de Arqueología cordobesa, 17, 2007, pp. 1-17.

${ }_{10}$ MORGADO, Alonso: Historia de Sevilla: en la qual se contiene su antigüedad, grandeza y cosas memorables... Sevilla, 1587, p. 11. 
marginalidad del barrio contribuirían con posterioridad las vías del ferrocarril y sus tapias. Este pequeño núcleo de población padeció desde sus orígenes las frecuentes inundaciones del arroyo, en el que se vertían toda clase de basuras y despojos ${ }^{11}$. Pese a ello se lavaba la ropa en sus orillas, como puede apreciarse en algunos grabados del siglo XVI. A todo ello hay que sumar, desde fines del siglo XV, la pestilencia del Matadero, del Quemadero y del Muladar, con los restos de las reses ${ }^{12}$. Ello contrastaba con los vecinos vergeles de Huerta del Rey y de la Buhaira. Un documento gráfico excepcional de este sector, que refleja los hechos antes citados, es el grabado calcográfico de Joris Hoefnagel, realizado hacia 1565, publicado por Georg Braun en Civitates Orbis Terrarum en 1572. La vista de Sevilla está tomada desde el sureste, sobre un montículo desaparecido, llamado del Rey. En su entorno se hallaba una horca, como puede apreciarse en el grabado editado por Brambilla (1585), y el Quemadero de los Herejes, sentenciados por el Tribunal de la Inquisición ${ }^{13}$.

La población de este arrabal entre las dos últimas décadas del siglo XVI y comienzos del XVII estuvo condicionada por dos hechos coyunturales: las epidemias de peste de 1580-1582 y la de 1599, más la inmigración, fundamentalmente de moriscos, negros y mulatos. El año de 1580 se le denominó "del moquillo". Por su causa fallecieron en la ciudad 12.000 habitantes, de los que 150 se enterraron en San Bernardo. En 1588 Sevilla llegó a tener más de 120.000 habitantes, de los que vivían en esta collación 400 vecinos en 158 casas $^{14}$. La ermita tenía pila bautismal desde $1558^{15}$. Entre 1570-1599 se bautizaron en ella 1.484 niños, de los que 1.241 eran cristianos viejos, 124 moriscos, 103 ilegítimos y 16 negros o mulatos. Los moriscos procedían principalmente de los reinos de Granada y

${ }^{11}$ Hubo un proyecto de urbanización del Tagarete en 1728 por el ingeniero Ignacio Sala y de encauzamiento y cubrición por el arquitecto Balbino Marrón en 1849. MORALES SÁNCHEZ, José: La Real Fábrica de Tabacos..., op. cit., pp. 161 y 179, nota 170.

12 Véase CARMONA, Juan Ignacio: Crónica urbana del malvivir (s. XIV-XVII). Insalubridad, desamparo y hambre en Sevilla. Sevilla, 2000.

${ }^{13}$ CABRA LOREDO, María Dolores: Iconografia de Sevilla (1400-1650). Madrid, 1988, pp. 64-66; VERA ARANDA, Ángel L.: "El barrio de San Bernardo (Sevilla)", Revista de Estudios Andaluces, 10, 1988, pp. 109-136; y FALCÓN MÁRQUEZ, Teodoro (edit.): $C a$ tálogo de la exposición Universidad de Sevilla (1505-2005). Sevilla, 2005, pp. 72-73.

${ }_{14}$ DOMÍNGUEZ ORTIZ, Antonio: Orto y ocaso de Sevilla. Sevilla, 1974, p. 160. El dato procede de GONZÁLEZ, Tomás: "Censo de población de España en el siglo XVI". Madrid, 1829, según datos obtenidos del Archivo General de Simancas.

15 APSB (Archivo de la parroquia de San Bernardo), Libro de bautismos $n^{o} 1,2$ y 3 , 1570-1610. En él se hallan insertas algunas hojas de años anteriores. Copiamos la primera partida: "En diez y nuebe de junio de mil e quinientos y cinquenta y ocho años, baptizé yo el doctor Diego de Torres cura de Sambernardo a Catalina, hija legítima de Juan Martín y de su mujer Luzía Martín. Fueron sus padrinos Martín Sánchez Alonso de Antequera y Ysabel Hernández”. 
Almería ${ }^{16}$. Del templo medieval apenas tenemos noticias. Es posible que el documento gráfico más antiguo que tengamos de él date de 1548. Corresponde a una ilustración del Libro de Grandezas y cosas memorables de España, de Pedro de Medina, que se halla en el capítulo titulado "Insigne ciudad de Sevilla, su antigüedad y nobleza" ${ }^{17}$. En esa vista de Sevilla figura en este lugar un pequeño templo de una nave, con cubiertas a dos aguas y contrafuertes exteriores. Entonces debió ser una iglesia gótico-mudéjar. Muestra torre almenada a los pies, lado de la epístola, más un campanario en la cabecera de ese frente. Es posible que en su origen fuese una iglesia fortificada, característica de los templos ubicados a extramuros, como lo fueron las iglesias de Santa Ana de Triana, y la del monasterio de San Isidoro del Campo, en Santiponce ${ }^{18}$. En ella se estableció una hermandad y cofradía, dedicada a San Bernardo y a la Virgen del Patrocinio, de la que se tienen noticias desde mediados del siglo XV. Entre la ermita y la Huerta del Rey hubo un cementerio, tal vez de conversos, que según Antonio Collantes fue expropiado por Orden Real en $1482^{19}$. La ermita pasó a pertenecer al cabildo catedral, según protocolo suscrito en 29 de octubre de 1593, ante el escribano público de Sevi1la Gaspar de León ${ }^{20}$. El documento se firmó de una parte por el deán y cabildo catedral y, por otra, por don García Álvarez de Sotomayor, prior de la ermita y canónigo de la catedral, quien "cede renuncia y traspasa perpetuamente" el templo al cabildo para que administre los sacramentos y se convierta en una capilla perteneciente a la catedral, ayuda de la iglesia del Sagrario. Entre las condiciones se estipula que la vivienda del prior, que se comunica con la capilla mayor,

${ }^{16}$ FERNÁNDEZ CHAVES, Manuel y PÉREZ GARCÍA, Rafael: En los márgenes de la ciudad de Dios. Moriscos en Sevilla. Valencia-Granada-Zaragoza, 2009, p. 492. En el libro 1 de bautismos consta que por la epidemia de peste solo en 1580 se bautizaron 40 niños, de los que eran varones 25 y 15 niñas. Predominan los nombres de Juan y de María. Por su singularidad transcribimos dos partidas del libro 1 de bautismos, 20-3-1593, f. 19v: "Antón, negro esclavo del Corço. Fue su padrino Hieronymo Hernandez, jardinero de el Corço. A este negro llaman Antón Bayón, que es negro viejo, y alto de cuerpo con una pierna gorda". 28-10-1593, f. 23v: "Exorzisé y cathechizé a Martín, hijo legítimo de Bartolomé Prieto y de Catalina Ximenez, vezinos de esta collación dentro del jardín que fue de Luis Pérez de Flandes. Fueron sus padrinos el maestro Martin Artacho, racionero de la Santa Iglesia Maior de esta ciudad de Sevilla y Ynes de Aranda vecinos de San Ysidoro. Ya avia baptizado a esta niña la partera porque ubo necessidad".

${ }^{17}$ CABRA LOREDO, María Dolores: Iconografía de Sevilla..., op. cit., lám. 13.

${ }_{18}$ FALCÓN, Teodoro: "Antecedentes sevillanos de iglesias fortificadas mexicanas", en II Jornadas de Andalucía y América. Sevilla, 1984, pp. 399-409; y FALCÓN, Teodoro: "La iglesia de Santa Ana: de edificio fortificado a templo barroco", en Santa Ana de Triana: Aparato histórico-artístico. Sevilla, 2016, pp. 360-381.

19 COLlAnTES DE TERÁN, Antonio: Sevilla en la Baja Edad Media. La ciudady sus hombres. Sevilla, 1977, pp. 99-101.

${ }^{20}$ ACS (Archivo de la catedral de Sevilla), sección IX, leg. 10967, exp. 8. 
debería seguir utilizándola este "por los días de su vida". Asimismo se informa que la iglesia se hallaba en ruinas, por lo que se le cede al cabildo la renta de unos solares que pertenecieron a Lázaro Martínez de Cózar y a su esposa María de Guzmán, para que pueda "repararla, ornamentarla y darle lo necesario". En un documento del año siguiente, fechado en 16 de diciembre de 1594, se especifica que la ermita "está caída y derribada, y todo su edificio en tierra"; entonces se había trasladado el Santísimo y todos los enseres a una casa del barrio ${ }^{21}$. A raíz de su reconstrucción, al nuevo edificio se le denomina "iglesia parroquial de San Bernardo, extramuros de esta ciudad, capilla de la catedral"22.

\section{LA IGLESIA MANIERISTA DE FINES DEL SIGLO XVI Y COMIENZOS DEL XVII}

En el último quinquenio de 1590 se debió iniciar el nuevo templo, de mayores proporciones y estética manierista. Para Cruz Isidoro, ratificado por Recio Mir, debió iniciarse a partir de 1593, según proyecto de Asensio de Maeda (1547¿1607?), maestro mayor de la catedral de Sevilla y su arzobispado, dirigiendo las obras como aparejador Miguel de Zumárraga ${ }^{23}$. Ya hemos indicado que todavía en 1594 se hallaba derribada. Como referencia de cómo debió ser ese nuevo templo de San Bernardo, podemos relacionarlo con otro que este arquitecto proyectó por estos mismos años, la iglesia del hospital de la Misericordia de esta ciudad, trazada por Maeda en 1595 y concluida en 1606. Se trata de una iglesia columnaria, de tres naves, con bóvedas de cañón con lunetos en la nave central y de aristas en las laterales, ambas decoradas con yeserías con motivos geométricos ${ }^{24}$. Es posible que Maeda repitiera en San Bernardo una serie de motivos de portadas y ventanas, análogos a los que diseñó en las dependencias capitulares de la catedral, a base de frontones semicirculares rebajados, sobre ménsulas manieris$\operatorname{tas}^{25}$. A causa de las ausencias de este arquitecto, establecido temporalmente en

${ }^{21}$ AGAS (Archivo General del Arzobispado de Sevilla), sección Gobierno, leg. 05284. El documento ha sido transcrito por VALENCIA JAPÓN, Víctor: "San Bernardo en la Sevilla del siglo XVI: Una nota documental inédita", Boletín de la Hermandad de San Bernardo, 129, 2015, pp. 6-11.

22 ACS, sección IV: Fábrica, lib. 05206.

${ }^{23}$ CRUZ ISIDORO, Fernando: Arquitectura sevillana del siglo XVII. Maestros Mayores de la catedral y del Concejo Hispalense. Sevilla, 1997, p. 36; y RECIO MIR, Álvaro: "Asensio de Maeda", en Proyecto Andalucía. Artistas y artífices del arte andaluz. El ciclo humanista. Desde el último gótico al fin del barroco. T. XXXXVI. La Coruña, 2011, pp. 38-69.

${ }^{24}$ ALBARDONEDO FREIRE, Antonio: "La iglesia nueva del Hospital de la Misericordia. Un proyecto de Asensio de Maeda con importantes colaboraciones (1595-1606)", Laboratorio de Arte, 16, 2003, pp. 67-105.

${ }^{25}$ FALCÓN, Teodoro: La catedral de Sevilla. Estudio arquitectónico. Sevilla, 1981, pp. 52-53, 56-57, 73-74 y 150-152; MORALES, A. J.: "La catedral de Sevilla en los siglos 
Valladolid y Granada, fue cesado por el cabildo catedral hispalense. Entonces Zumárraga ejerció en funciones el oficio de maestro mayor de la catedral, desde 1602 hasta su nombramiento definitivo en 1620. En cabildo catedral de 7 de septiembre de 1609, se acordó: "Que a la capilla de San Bernardo se le de lo necesario a[1] parecer de la Contaduría y del Sr. Don Manuel Sarmiento de Mendoza, y se ponga un campanario"26. Zumárraga debió ser, al menos, el artífice de esta torre $^{27}$. En los grabados del siglo XVII figura como un nuevo templo de escala monumental, con visos de estar fantaseado. Es el caso, por ejemplo, de la "Vista panorámica de Sevilla", de 1617, editada por Joannes Janssonius ${ }^{28}$. En las afueras de la ciudad consta "St. Bernaldo", como un edificio fuera de escala, con dos altas torres en la cabecera y otras tantas a los pies. Del mismo modo se repite en una vista de Sevilla de 1643, con el lema "HISPALIS VULGAIREMENT SEVILLE VILLE ARCHIEPISCOPALLE MAGAZIN DES INDES ET CAPPITALLE DANDALVZIE"29.

A comienzos del XVII hubo un notable incremento de la población en este arrabal, en el que se establecieron negros, esclavos, moriscos ${ }^{30} \mathrm{y}$ extranjeros, principalmente portugueses y flamencos, como documentó Carriazo, basándose en el libro I de bautismos (1570-1610), en el libro II de matrimonios (1608-1638) y en el

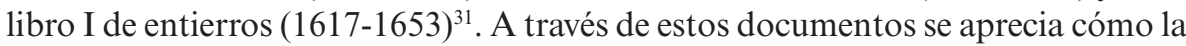
modesta población tenía su principal actividad en el Matadero; en huertas, entre

XVI, XVII y XVIII", en La catedral de Sevilla. Sevilla, 1984, pp. 201-211; y RECIO MIR, Álvaro: Sacrum Senatum. Las estancias capitulares de la catedral de Sevilla. Sevilla, 1999.

${ }^{26}$ ACS, sección I: Autos capitulares 45, f. 31v; y CRUZ ISIDORO, Fernando: Arquitectura sevillana..., op. cit., p. 36.

${ }^{27}$ FALCÓN, Teodoro: La capilla del Sagrario de la catedral de Sevilla. Sevilla, 1977, pp. 43-44; y FALCÓN, Teodoro: La catedral de Sevilla, op. cit., pp. 150-153.

${ }^{28}$ CABRA LOREDO, María Dolores: Iconografía de Sevilla..., op. cit., pp. 133-136; y FALCÓN, Teodoro: Catálogo de la exposición El emporio de Sevilla. IV Centenario de la construcción de la Real Audiencia. Sevilla, 1995, nº 32.

${ }^{29}$ CABRA LOREDO, María Dolores: Iconografía de Sevilla..., op. cit., pp. 192-194.

30 A causa de ser deportados de Granada tras la guerra de las Alpujarras, en 1580 llegó a haber en esta ciudad 6.000, de los que se establecieron en San Bernardo 350. En 1610 se deportaron 7.500 según Domínguez Ortiz. En esta feligresía habían en este año 170 moriscos (62 hombres, 67 mujeres y 41 niños). FERNÁNDEZ CHAVES, Manuel y PÉREZ GARCÍA, Rafael: En los márgenes de la ciudad..., op. cit. p. 489; FERNÁNDEZ CHAVES, Manuel y PÉREZ GARCÍA, Rafael: "San Bernardo Morisco: familia, ocupación del espacio urbano y movilidad de una minoría en la Sevilla de Felipe II", en XI Simposio Internacional de Mudejarismo. Teruel, 2008, pp. 825-836; y FERNÁNDEZ CHAVES, Manuel y PÉREZ GARCÍA, Rafael: "Ensayo de reconstrucción urbana: collación de San Bernardo. Siglos XVII-XVIII", en Actas del III Congreso de Historia de Andalucía. Córdoba, 2001.

${ }^{31}$ CARRIAZO, Juan de Mata: "Negros, esclavos y extranjeros en el barrio sevillano de San Bernardo (1617-1629)", Archivo Hispalense, 64-65, 1954, pp. 121-133. 
las que se citan la de la Ternera, de Tablada, del Alcázar y del Rey; y en hornos, de Valenzuela, del Rincón, del Moral y de los Ocho Hornos -calle Marqués de Estella-. Entre las calles se aluden a la Larga, Ancha y del Cura. Corrales de vecinos, del Concejo, del Veinticuatro, del Cura y de las Cruces; mesones, de la Ramada y de las Tablas; ventas, de la Negra y de Sosa; tabernas, del Cantillo y del Marmolillo, además de la "Casa de las beatas" y la "Casa de los frailes de la Paz". Los entierros se hacían en la iglesia, habiendo en esta época gran mortandad infantil. En 1619, cuando prácticamente estaba concluido el segundo templo, como veremos, se enterraron 117 personas, de las cuales 47 eran niños. Hay indicios suficientes sobre esta iglesia, que evidencian que debió concluirse hacia 1620. De esta década datan las piezas artísticas más antiguas, que atesora la hermandad sacramental de este templo, que estuvo estrechamente vinculada a la de las Ánimas Benditas del Purgatorio. En la entrada de la capilla de la cabecera, nave del evangelio del edificio actual, hay una lápida con la siguiente inscripción: ESTA CAPILLA Y SUS SEPULTURAS SON DE LAS COFRADÍAS DEL SANTÍSIMO SACRAMENTO Y DE LAS ÁNIMAS DEL PURGATORIO DEL SR. S. BERNARDO. ACABÓSE AÑO DE 1621.

El lienzo de la Sagrada Cena, de Francisco Varela, está firmado y fechado en 1622. El del Juicio Final, de Herrera el Viejo, está documentado en 1628. Asimismo es de Herrera La Flagelación de Cristo, que presidió la anterior capilla sacramental en 1629, junto con una Entrada de Cristo en Jerusalén. De las piezas de orfebrería de esta hermandad, fusionada en 1967 con la del Cristo de la Salud, las más antiguas son dos ostensorios, fechados respectivamente en sendas inscripciones en 1620 y $1621^{32}$. Los libros de visitas conservados en el archivo catedral dan noticias puntuales de algunas reformas llevadas a cabo en el templo a lo largo del siglo XVII hasta su derribo en 1780, así como de la ubicación en él de determinadas dependencias y de la dotación de su mobiliario artístico. Estimo que tenía la orientación litúrgica preceptiva oeste-este. En la visita del templo verificada por el canónigo don Francisco Maldonado en 5 de abril de 1690, manifiesta que pasó a

${ }^{32}$ LÓPEZ MARTÍNEZ, Celestino: Arquitectos, escultores y pintores vecinos de Sevilla. Sevilla, 1928, pp. 63-65; LÓPEZ MARTÍNEZ, Celestino: Retablos y esculturas de traza sevillana. Sevilla, 1928, p. 150; LÓPEZ MARTÍNEZ, Celestino: Desde Martínez Montañés hasta Pedro Roldán. Sevilla, 1932, p. 187; HERNÁNDEZ DÍAZ, José y SANCHO CORBACHO, Antonio: Estudio de los edificios religiosos y objetos de culto de la ciudad de Sevilla, saqueados y destruidos por los marxistas. Sevilla, 1936, p. 153; MARTÍNEZ RIPOLL, Antonio: Francisco de Herrera el Viejo. Sevilla, 1978, pp. 94-97; VALDIVIESO, Enrique y SERRERA, Juan Miguel: Catálogo de la exposición La época de Murillo. Antecedentes y consecuentes de su pintura. Sevilla, 1982, $\mathrm{n}^{\circ} 15$, pp. 64-65; VALDIVIESO, Enrique y SERRERA, Juan Miguel: Pintura sevillana del primer tercio del siglo XVII. Madrid, 1985, p. 248; SANZ SERRANO, María Jesús: La Orfebrería sevillana del Barroco. T. II. Sevilla, 1976, p. 135; y RODA PEÑA, José: Hermandades Sacramentales de Sevilla. Una aproximación a su estudio. Sevilla, 1996, pp. 123-125. 
visitar el sagrario "que está a la mano siniestra de la iglesia", como se halla en la actualidad. La pila bautismal estaba "a la mano diestra de la puerta principal" En 11 de noviembre de 1648 se tasaron en 770 reales unos reparos en el templo, que duraron todo el invierno y primavera siguiente, para lo que se necesitaron otros 700 reales. Fueron llevados a cabo bajo la dirección del maestro mayor Pedro Sánchez Falconete ${ }^{34}$. El maestro ensamblador Martín Moreno realizó el candelabro de tinieblas en $1650^{35}$. Es el mismo artífice del retablo de la Concepción Grande de la catedral y del retablo mayor de la iglesia de Santa María la Blanca, en donde hizo también la sillería de coro, desaparecida en la segunda mitad del siglo XIX ${ }^{36}$. En 1651 Martín Moreno rehízo el monumento de Semana Santa de San Bernardo, con la colaboración del maestro dorador Francisco Sánchez ${ }^{37}$.

En la primavera de 1649, Sevilla, como el resto de las poblaciones andaluzas, padeció los estragos de una devastadora epidemia de peste negra o bubónica, que afectó dramáticamente a su población, que pasó de 120.000 a 60.000 habitantes $^{38}$. Este hecho la convirtió en una ciudad fantasma. Entre los fallecidos destacan el arzobispo Agustín de Spínola, el arcediano Mateo Vázquez de Leca, el escultor Martínez Montañés, los ensambladores Luis Ortiz de Vargas y Jerónimo Velázquez, el pintor Juan de Zurbarán, hijo del pintor de Fuente de Cantos, la esposa del escultor José de Arce y la del ensamblador Francisco Dionisio de Ribas, así como tres hijos de Murillo, entre otros. En la feligresía de San Bernardo el momento crítico de la epidemia tuvo lugar en el mes de mayo. Según una memoria escrita por el párroco de entonces, fallecieron en esta feligresía en ese mes 275 personas, que se enterraron en el templo, en el cementerio de la parroquia y en la capilla sacramental. Otros cadáveres se sepultaron en las iglesias de San Sebastián, en el convento de Portaceli y en Santa María la Blanca. El hecho de que se trasladaran al hospital de la Sangre un número considerable de afectados de landres -carbunco o bacilo de ántrax-y de tabardillos -tifus exantemático-, donde fallecieron, permitió inferir a este presbítero que debieron fallecer en ese mes más de 500 feligreses. A ello añadiremos que en el mes de junio perecieron en este barrio 154 personas más. El punto más álgido tuvo lugar el día 13, con 21 defunciones,

33 ACS, sección IV: Visitas, lib. 05195, f. 62.

${ }^{34}$ CRUZ ISIDORO, Fernando: Arquitectura sevillana ..., op. cit., p. 88.

35 ACS, sección IV: Visitas, lib. 05193, f. 8v: "De un candelero para el cirio pascual y para las tinieblas, que no lo había en la iglesia, $225 \mathrm{rs}$. vn. Consta de carta de pago de Martín Moreno, maestro ensamblador y arquitecto, dada en 26 de abril de 1650. Y de pintarlo pago a Francisco Sánchez, veinte reales".

${ }^{36}$ FALCÓN, Teodoro: "El arquitecto de retablos y escultor Martín Moreno y los primeros retablos con columnas salomónicas en Sevilla", Boletín de Arte, 34, 2013, pp. 69-87; y FALCÓN, Teodoro: La iglesia de Santa María la Blanca y su entorno. Arte e Historia. Sevilla, 2015, pp. 75-76 y 107-111.

37 ACS, sección IV: Visitas, lib. 05193, ff. 13v-14v.

38 Véase CARMONA GARCÍA, Juan Ignacio: La peste en Sevilla. Sevilla, 2005. 
decreciendo considerablemente en días sucesivos ${ }^{39}$. El libro de entierros nos permite conocer los nombres de algunas calles de entonces (Ancha y Plazuela de la Iglesia). Corrales de vecinos: de Alberto Rodríguez, de los Alemanes, del Azofaifo, del Botero, de los Bueyes, del capitán Arnao, el Corral Chico y el Grande del Veinticuatro, el del Consejo, de las Luces, de las Higueras, primer corral de la Moraleja, el Nuevo y el del Rincón; hornos: de Basilio Rincón, de Catalina Méndez, de Luis Morel, del Bizcocho, Ocho Hornos y el Hornillo; huertas: del Aceñuelo, de las Palmas (Jardín de la Huerta de las Palmas), del Retiro del Alcázar y del Rey; además de lugares: Tienda del Mármol, Alcantarilla del Tagarete, hacienda y heredad del Corzo y San Telmo. Todo ello permite apreciar cómo la feligresía se extendía hasta lugares periféricos.

Son frecuentes en los libros de visitas del archivo catedral cargos de gastos menores para solar la iglesia y las sepulturas. En 1649 consta este pago: "De solar 18 sepulturas en el cuerpo de la iglesia, a 19 rs. cada una, que importaron 836 rs. vn." ${ }^{40}$. En 1677 se pagaron 330 reales "que se gastaron en solar la iglesia, con un millar de ladrillos, un cahiz de cal y demás gastos de albañilería" ${ }^{41}$. En 1679 se pagaron al enterrador Andrés Muñoz 114 reales "por trasladar los huesos de las sepulturas de la iglesia al cementerio" (camposanto) ${ }^{42}$. En 1690 el maestro cantero Francisco Jordán hizo la losa de mármol para la bóveda del coro ${ }^{43}$ y de 1770 hay pagos "por los gastos de sepulturas de los cofrades del Santísimo" frecuentes las minutas por renovar los alizares (azulejos) de las gradas de acceso al altar mayor: en 1662, 1677 y $1684^{45}$, entre otros años. En este último se pagaron a un maestro albañil 40 reales "por renovar las gradas del presbiterio, el empedrado de la puerta de la iglesia y resanar los tejados"46. En 8 de marzo de 1674 el cabildo catedral encomendó al canónigo-presidente de las capillas Luis Federigui para que se construyera una dependencia para almacenar el monumento del Jueves Santo. Fue realizado bajo la dirección de Esteban García, maestro mayor de la catedral y del arzobispado ${ }^{47}$. Por otra parte citaremos el dato de la restauración del retablo "del Santo Cristo" en 1668, "por habérsele caído la peana del altar" ${ }^{\prime 2}$. Ese retablo sería sustituido en 1692 por el actual, como veremos más

39 APSB, Libro I de entierros, 1617-1653, ff. 54v-ss.

40 ACS, sección IV: Visitas, lib. 05193, f. 6r.

${ }^{41}$ Ibidem, f. 202. En este año el cabildo catedral dio orden para que esta iglesia tuviera organista "como en las demás capillas [de la catedral]". ACS, sección 0, tomo 94, lib. 07040, f. 104.

${ }^{42}$ Ibidem, f. $232 \mathrm{v}$.

${ }^{43}$ ACS, sección IV: Visitas, lib. 05195, f. 74.

${ }^{44}$ ACS, sección IV: Visitas, lib. 05206, f. 83.

${ }^{45}$ ACS, sección IV: Visitas, lib. 05193, ff. 63-68, 144-145, 168v y 202v.

46 ACS, sección IV: Visitas, lib. 05195, f. 13v.

${ }^{47}$ CRUZ ISIDORO, Fernando: Arquitectura sevillana..., op. cit., p. 118.

${ }^{48}$ ACS, sección IV: Visitas, lib. 05193, f. 168v. 
adelante. A fines de ese siglo destacaremos el "reparo mayor" del templo, que llevó a cabo el maestro mayor Juan Domínguez en 1690, cuyo coste ascendió a 1.524 reales y medio de vellón. Entonces amenazaban ruina las cubiertas sobre la puerta principal, y "se aderezó la pared sobre que estaba el campanario"49. Juan Domínguez (†1691) fue maestro alarife, maestro mayor superintendente de la catedral y maestro mayor del arzobispado. De su amplia actividad destaca la dirección de las obras del hospital de los Venerables Sacerdotes, que llevó a cabo entre 1676 a $1686^{50}$. En 1699 se hizo un nuevo retablo mayor, realizado por Juan de Valencia, que se estrenó el día de San Bernardo ${ }^{51}$. Juan de Valencia (h. 1660-1738) fue un maestro escultor y ensamblador discípulo y yerno de Bernardo Simón de Pineda. De su labor destacan los retablos mayores de las iglesias del Salvador de Carmona, de Santa María la Blanca de La Campana y de la parroquia de Bornos (Cádiz). Intervino en las sillerías de coro de la Cartuja de Sevilla y de San Juan de Marchena, en donde realizó también el facisto ${ }^{52}$. Son también frecuentes los pagos para mantener alumbrado el altar mayor de San Bernardo con una lámpara, alimentada con 6 arrobas de aceite al año ${ }^{53}$. En la década de 1750 se llevaron a cabo diversos reparos y mejoras, entre los que destacamos el abrir una ventana en la sacristía en 1752, mejoras en el porche en 1751 y 1758, así como reparos en el campanario en $1758^{54}$.

Del edificio anterior se conservan en el actual tres retablos, de los cuatro que realizó Fernando de Barahona entre 1685-1692. El retablo mayor que hizo en 1685 fue sustituido por otro, anterior al actual. Era de tipo marco, flanqueado como todos los suyos por columnas salomónicas, semejante al que había ejecutado en 1676 para la capilla de la hermandad de las Ánimas del Purgatorio de la iglesia de San Lorenzo. En 1729 fue sustituido por otro, realizado por Bartolomé García de Santiago. De todos los trazados por este ensamblador, el único que se conserva es el retablo mayor de la iglesia de La Algaba, de 1731. Su estructura es a base de estípites, con decoración de hojas de cardo. En los extremos del crucero del templo actual se conservan dos retablos prácticamente idénticos. El del

49 ACS, sección IV: Visitas, lib. 05195, ff. 16v-17r.

${ }^{50}$ SANCHO CORBACHO, Antonio: Arquitectura barroca..., op. cit., pp. 49-54; CRUZ ISIDORO, Fernando: Arquitectura sevillana..., op. cit., pp. 123-129; y FALCÓN, Teodoro: "El Hospital de Venerables Sacerdotes de Sevilla. Algunas consideraciones sobre el edificio y el papel desempeñado por los arquitectos Juan Domínguez y Leonardo de Figueroa", Laboratorio de Arte, 30, 2018, pp. 125-149.

${ }^{51}$ ACS, Sección IV: Visitas, lib. 05195, ff. 215r, 221v, 222r y 228r-v.

${ }^{52}$ HERRERA GARCÍA, Francisco J.: El retablo sevillano en la primera mitad del siglo XVIII. Sevilla, 2001, pp. 294-295; y HALCÓN, Fátima; HERRERA, Francisco y RECIO, Álvaro: El retablo sevillano desde sus orígenes a la actualidad. Sevilla, 2009, pp. 250-253.

${ }_{53}$ ACS, sección IV: Visitas, lib. 05202, f. 107r.

${ }^{54}$ Ibidem, ff. 122, 123 y 176. 
lado de la epístola fue construido por Barahona en 1692. Es de un cuerpo y se enmarca entre columnas salomónicas. Preside la talla del Cristo de la Salud, titular de la hermandad de penitencia. Fue realizado en 1669 por Andrés Cansino. Procede de la Escuela del Espíritu Santo, que radicaba en la calle Tetuán. Vino a sustituir en 1938 a la imagen primitiva, que fue quemada el 11 de julio de 1936. En el ático se halla la imagen del arcángel San Rafael. En el lado opuesto, nave del evangelio, se ubica el retablo de las Ánimas del Purgatorio. Aunque no está documentado, se le atribuye a Barahona por su semejanza con el de enfrente. Asimismo es de un cuerpo, flanqueado por columnas salomónicas, que enmarcan el monumental lienzo de las Ánimas del Purgatorio, realizado por Herrera el Viejo en 1628. En el ático figura la talla del arcángel San Miguel. Finalmente fue realizado por el mismo artífice el retablo de la Virgen del Patrocinio en 1690, situado en la cabecera de la nave de la epístola, que hace las funciones de capilla bautismal. Es de tres calles, flanqueadas también por columnas salomónicas. Son originales las tallas de San Antonio y de Santa Rita, además del relieve de la Visitación en el ático ${ }^{55}$. En los libros de visitas se alude a otras capillas y retablos. Así en 1770 se documenta la realización de la reja de la capilla de Nuestra Señora de los Reyes, y en 1776 se cita la lámpara del altar de la Encarnación ${ }^{56}$. Pedro Duque Cornejo realizó entre 1715-1716 el sagrario-manifestador, flanqueado por estípites, entre los cuales figuran las tallas de los santos Juanes, abajo, y las de Santo Tomás y San Agustín arriba, además de los relieves alusivos a La entrega del rosario a Santo Domingo y La lactación de San Bernardo. Este sagrario quedó incorporado en el actual, realizado en 1785 por Manuel Barrera y Carmona ${ }^{57}$.

Las gestiones para la construcción del nuevo templo se iniciaron cinco años antes del comienzo de las obras. En 14 de septiembre de 1775 se comisionó por el cabildo catedral a José Álvarez, maestro mayor del templo metropolitano, y a José García, maestro alarife, para que reconocieran unas casas adosadas al

${ }_{55}^{5}$ LÓPEZ MARTÍNEZ, Celestino: Arquitectos, escultores y pintores..., op. cit. pp. 63-65; HERNÁNDEZ DÍAZ, José: "Papeletas para la historia del retablo en Sevilla durante la segunda mitad del siglo XVII (Francisco Dionisio de Ribas. Bernardo Simón de Pineda. Fernando de Barahona)", Boletín de Bellas Artes, 2, 1935, pp. 2-8; HERNÁNDEZ DÍAZ, José y SANCHO CORBACHO, Antonio: Edificios religiosos..., op. cit., p. 153; MARTÍNEZ RIPOLL, Antonio: Francisco de Herrera..., op. cit., pp. 123-125; VALDIVIESO, Enrique y SERRERA, Juan Miguel: Pintura sevillana del primer tercio..., op. cit., p. 247; RODA PEÑA, José: Hermandades Sacramentales..., op. cit., pp. 123-125; CARO QUESADA, María Salud: Noticias de Escultura, en Fuentes para la Historia del Arte Andaluz. T. III. Sevilla, 1992, p. 201; y HALCÓN, Fátima; HERRERA, Francisco y RECIO, Álvaro: El retablo barroco sevillano. Sevilla, 2000, p. 325.

${ }^{56}$ ACS, sección IV: Visitas, lib. 05206, ff. 12 y $137 \mathrm{v}$.

57 HERNÁNDEZ DÍAZ, José: Pedro Duque Cornejo y Roldán (1678-1757). Sevilla, 1983, pp. 44-55; y RODA PEÑA, José: "Pedro Duque Cornejo en la Capilla Sacramental de la parroquia de San Bernardo de Sevilla", Laboratorio de Arte, 11, 1998, pp. 571-583. 
edificio primitivo, cuyo solar tras su derribo, permitiría aumentar el espacio de la nueva iglesia. Se trata de tres casas pertenecientes al patronato y capellanía fundada por el capitán Juan de Cáceres Hidalgo, natural de la villa de Castuera (Badajoz), de las cuales el cabildo adquirió dos con posterioridad. El documento se formalizó ante el escribano público de Sevilla Luis León Pérez en 17 de mayo de 1780. En el reconocimiento realizado por el maestro mayor y el alarife se describen en primer lugar unas casas grandes, contiguas al testero de la sacristía de la iglesia. Era de dos plantas, con habitaciones en torno a un patio, más corral. Fue evaluada en 20.000,10 reales de vellón. La vivienda más pequeña se componía de tres estancias en planta baja y dos altas, también con su corral. Su precio se tasó en 13.200 reales de vellón. En la escritura se especifica que la adquisición de las dos viviendas es "para la reedificación y extensión de la iglesia parroquial de $\mathrm{Sr}$. San Bernardo" 58 . Aunque en 1776 José Álvarez restauró el viejo edificio y se pensó comenzar entonces el actual, el proceso se dilató por espacio de cuatro años, a causa de un pleito entablado por Vicente Palomeque y su esposa, contra la capellanía y patronato de Juan Cáceres. El proyecto del nuevo templo fue presentado por José Álvarez en cabildo catedral de 10 de mayo de 1780. Consta de planta y sección longitudinal, con las condiciones para su ejecución, evaluando el presupuesto en 520.000 reales de vellón ${ }^{59}$. Por sus trazas percibió 400 reales de vellón ${ }^{60}$.

Fecha de recepción: 25 de octubre de 2018

Fecha de aceptación: 5 de febrero de 2019

\footnotetext{
${ }^{58}$ ACS, sección IX, leg. 10.967, exp. 8.

${ }^{59}$ HIGUERA MELÉNDEZ, José Manuel: “José Álvarez...”, op. cit., pp. 368, 369 y 382.

${ }^{60}$ ACS, sección VI: Contaduría, leg. 12316, exp. 2: "Digo yo Joseph Albarez, Maestro Mayor de obras, que recivi quatrocientos rs. vn por el tiempo que me e ocupado en los Planos y Alzados y condiciones para la construcción de la nueva Iglesia Parroquial del Sr. S. Bernardo, extramuros de esta ciudad, y capilla de esta Santa Iglesia, y asi como otras diligencias anteriores que tengo hechas de otras obras y aprecios de casas, que se incluye a el sitio que a de ocupar la Iglesia. Sevilla y Mayo 24 de 1780. Joseph Alvarez [firmado y rubricado]".
} 